\title{
Rural and non-rural digital divide persists in older adults: Internet access, usage, and attitudes toward technology
}

\author{
Hee Yun Lee PhD MSW ${ }^{a}$, Shaheen Kanthawala $\mathrm{PhD}^{\mathrm{b}}$, Eun Young Choi $\mathrm{MA}^{\mathrm{c}}$, Young \\ Sun Kim $\mathrm{PhD}^{\mathrm{d}, *}$ \\ ${ }^{a}$ School of Social Work, the University of Alabama, Tuscaloosa, USA; ${ }^{b}$ Department of \\ Journalism \& Creative Media, the University of Alabama, Tuscaloosa, USA; 'School of \\ Gerontology, University of Southern California, Los Angeles, USA; ${ }^{d}$ Department of Geron- \\ tology, AgeTech-Service Convergence Major, Kyung Hee University, Suwon, South Korea; \\ *Corresponding author: ysunkim@khu.ac.kr
}

\begin{abstract}
Background: The digital age divide remains persistent despite the recent increase in internet use among older adults. Additionally, older rural residents are at greater risk of being digitally disconnected.

Objective: Guided by the social determinants of health framework, our study aims to examine how one's residential area relates to (1) internet use, (2) subtypes of usage patterns, and (3) attitudes toward technology use in later life.

Method: Cross-sectional data were drawn from the 2012 Health and Retirement Study. The analytic sample consisted of 1,566 older adults aged 50 and above. Chi-square tests and logistic regression analyses were performed.

Results: Internet access rates were significantly lower in rural residents $(54 \%)$ compared to the urban $(66 \%)$ or the suburban group $(61 \%)$. Compared to urban residents, those residing in suburban areas were less likely to use health technology while those living in rural areas had lower odds of communication, financial, and media technology use. Furthermore, the association between urban-rural residence and attitudes toward technology was compared among non-users $(\mathrm{N}=633)$. Older adults in rural areas showed more unfavorable perceptions of technology than urban residents. They were less likely to conceive technology as "easily available," but more likely to perceive it as "too complicated" and "too hard to learn." No significant differences were found between rural and suburban residents.

Conclusion: Our findings suggest that older adults in rural areas, notably lag in using and adopting digital technology. Comprehensive intervention efforts are needed to narrow the digital divide for rural communities.
\end{abstract}

Keywords: technology, digital divide, rural, urban, attitude, older adults

\section{INTRODUCTION}

With the pervasive spread of technology and digital technologies used in every aspect of life, research has noted the development of a digital divide (Ball et al., 2019; van Dijk, 2006). As elaborated through these studies, a digital divide refers to a division in access to digital technologies for certain populations. More specifically, van Dijk and Hacker (2003) proposed four access-related gaps that might lead to a digital divide. The first was a mental gap, which refers to emotional or psychological gaps that emerge from people's lack of experience with digital technologies. Next was the material access gap, referring to the more traditional lack of access, such as lack of access to technologies. Third, they referred to a lack of skills, referring to how experience with technologies would increase an individual's technology skills. Lastly, they mention the usage gap, referring to differences in usage that lead to various usage patterns (such as simpler communication tasks only vs. more complex, social capital building tasks, for instance). Despite these multiple aspects of digital technology use, most previous studies on the digital divide have been primarily focused on accessibility (whether the participants can use the technology or not), leaving usage patterns and personal attitudes underexplored.

The digital divide literature has conceptualized three levels of the digital divide: (1) the first-level divide focusing on disparities in Internet access; (2) the second-level divide referring to unequal Internet skills and usage; (3) the third-level divide related to the outcomes of Internet use (van Dijk, 2020). While more recent research attention shifts towards the second-and third-level divide as mobile broadband becomes nearly ubiquitous, the first-level digital divide still calls for further investigation in the context of socio- 


\section{Urban/rural digital divide among older adults}

economic disparities (Gonzales, 2016). On the other hand, theoretical frameworks have suggested two distinct reasons for the non-use of the Internet. First, a lack of material resources may push individuals involuntarily away from Internet use (Livingstone \& Helsper, 2007). Second, psychological factors such as motivation, attitudes, and interest may drive individuals' voluntary decisions not to use digital technologies (van Dijk, 2005). Studies found that inequalities in Internet access are likely to be attributable to involuntary exclusion, while disparities in Internet skills and usage are also shaped by personal motivations and attitudes (Eynon \& Helsper, 2011; Yu et al., 2016). The current study aims to investigate the role of one's residential area in relation to the first- and second-level digital divides using a representative sample of older Americans. We consider internet access and specific types of technology usage as outcome variables. In addition, we focus on non-users of communication technologies to examine what contributes to their attitudes toward technology.

It is important to note that the digital divide is nuanced and shows different patterns of change depending on which aspects are considered: some digital gaps are narrowing down over the last few decades while others remain. For example, the rate of Americans who don't use the internet has decreased rapidly from $48 \%$ in 2000 to $7 \%$ in 2021 (Perrin \& Atske, 2021). Similarly, recent studies found that the vast majority of people have a smartphone or technological divide (Barrantes \& Vargas, 2017). While the general access to the internet or technology has been improved, individuals with low-income, rural residents, and minorities have a limited number of digital devices for online access and rely primarily on smartphones (Vogels, 2021a). They are also less likely to have broadband internet at home, creating other disparities such as educational and health inequalities (Ong, 2020; Vogels, 2021b).

The digital divide leads to the exclusion of populations based on different factors. Age has been a major leading factor in the digital divide, placing older adults into one of the largest affected populations (Tsai et al., 2015). As of 2019, 27\% of Americans aged 65 and older and 12\% of adults aged 50 to 64 were not using the internet, which is a sharp contrast to the nearly ubiquitous internet usage among young adults; 100\% of 18-29-year-olds and $97 \%$ of 30-49-year-olds reported using the internet (Pew Research Center, 2019). Although one of the largest populations affected by the digital divide is older adults (Tsai et al., 2015), digital technologies may be most beneficial to this population. Older adults' technology use spans various avenues of life. Using information and communication technologies (ICTs) has shown to have increased feelings of mattering among older adults (Francis et al., 2019), connecting them with loved ones (Heo et al., 2015; Quan-Haase et al., 2017; Sum et al., 2008), and assisting with managing their health through medical and health-related technologies (Levine et al., 2016; van Deursen, 2020). With increasing medical treatment improvements, older adults account for large percentages of both the U.S. and global populations. By 2030, 20\% of the U.S. population will be older adults - the largest population of older adults in U.S. history (Centers for Disease Control and Prevention., 2013). Given the beneficial effects of technology use and demographic changes, more research efforts are needed to close the older population's digital divide.

In addition to the generally low technology adoption rates among older adults, it is vital to understand the within-group heterogeneity. Those with lower socioeconomic status and poor health have been reported to be at greater risk of being excluded from technology use (Gell et al., 2015; Silver, 2014). Amongst various predictors of older adults' technology use, a recent growing body of literature has shown that rural living is significantly associated with limited access to the internet and electronic devices (Berner et al., 2015; Calvert et al., 2009). Moreover, in qualitative studies, older adults living in suburban or rural areas reported negative perceptions of using technologies, such that lack of knowledge about how technologies function or difficulty in learning how to use them greatly limited their use (Marston et al., 2019; O'Brien et al., 2014). Prior studies suggested low rural residents' socioeconomic status levels partly contributing to the urban-rural differences in technology use (Hale et al., 2010). However, underdeveloped infrastructure and broadband services in rural communities, which are related to high-speed internet access, can also result in their residents' limited technology use (Anderson, 2018; Greenberg et al., 2018; Korupp, 2005). Indeed, having access to technology, particularly high-speed internet, is a critical facilitator of older adults' technology use (Hanson, 2010; Marston et al., 2019).

The observed digital divide by age and residential area is well encapsulated in the social determinants of health framework (World Health Organization [WHO], 2010), which posits that the source of health inequities originates from "the conditions in which people are born, grow, work, live, and age, and the wider set of forces and systems shaping the conditions of daily life." (WHO, 2020, p.1). According to the framework, the digital divide could occur due to broader systemic and socioeconomic contexts and individual-level sociodemographic factors (i.e., age and gender). Thus, we argue that a geographic 
residence where older adults live would be an important social determinant of digital technology use by offering different opportunities and challenges embedded in regional infrastructure and community support.

\section{The present study}

Although prior studies suggested some valuable insights into the urban-rural digital divide for the older population, most relied on small convenient samples or measured a single aspect of technology use (i.e., internet access). In addition, there were few studies focused on different usage patterns or psychological factors. The current study aims to investigate whether one's residential area relates to (1) their internet use, (2) the subtypes of their technology usage patterns, and (3) their attitudes toward technology use. We conducted a series of regression analyses on data of a nationally representative sample of U.S. adults aged 50 or older. Building on the previous literature and the social determinants of health framework, we hypothesized the following:

Hypothesis 1: Older adults living in suburban and rural areas will use the internet less than their urban counterparts.

Hypothesis 2: Older adults living in suburban and rural areas will be less likely to use different technologies (communication, financial, health, and media) than urban residents.

Hypothesis 3: Older adults living in suburban and rural areas will have more unfavorable attitudes toward technologies than those residing in urban communities.

\section{Methods \\ Data and sample}

The Health and Retirement Study (HRS) is a nationally representative panel survey of approximately 20,000 Americans aged 50 or older. The HRS has been repeated biannually since 1992 . Participants are asked a wide range of questions on aging (e.g., health, jobs, retirement, and social relationships) through face-to-face or telephone interviews. The HRS's sampling design, survey procedures, and questionnaires are described in detail at the HRS website (http://hrsonline.isr. umich.edu). We retrieved the respondent's socioeconomic and health information from the RAND HRS data file, which is cleaned and processed by the RAND Center for the Study of Aging (Santa Monica, California). The RAND HRS data set provides imputed values for income and health status that were generated using all information available with a consistent imputation method.

In 2012, a randomly selected subsample of participants was administered to an experimental module that included questions about technology use and perceptions of the barriers and benefits. A total of 1,620 community-living adults aged 50 or older completed the module. We excluded 54 respondents $(3.33 \%)$ who had missing data on covariates, internet access, and internet usage variables, which resulted in an analytic sample of 1,566 individuals. Among the respondents, those who did not use any communication technologies such as email and social network sites $(\mathrm{N}=$ 633) were further asked about their attitudes toward technology. We use this subsample of respondents for the analyses of non-users ' attitudes toward technology. Ethical approval for the HRS was obtained from the University of Michigan Institutional Review Board and the National Institute on Aging. All respondents have given their written informed consent before the data collection.

\section{Measures}

Internet access

Participants' internet access was assessed with a single item: "Do you regularly use the Internet (or the World Wide Web) for sending and receiving email or for any other purpose, such as making purchases, searching for information, or making travel reservations?" Responses were coded as $1=$ yes or $0=$ no.

\section{Technology usage}

Technology usage was measured by a checklist of various kinds of electronic technologies. The list included fifteen items ( 1 = yes for each), which can be grouped into four broad types of technology: (1) communication technology (i.e., email, social networks, online calls, online chatting, and smartphone); (2) financial technology (i.e., online bill payment and online banking); (3) health technology (i.e., online wellness program, online health information seeking, devise use of health monitoring, and Wii fit use); and (4) media technology (i.e., e-readers/tablets, MP3 players, live-streaming radio, T.V., or movies, and video games). Responses were dichotomized for each technology category, where $0=$ non-user and 1 = users who checked one or more technology items in a given category.

\section{Attitudes toward technology}

Participants who reported no use of any communication technologies, or non-users, were further asked about their attitudes toward technology. They answered yes or no to eight questions: (1) if they would be interested in trying any communication technologies, (2) whether technology is too expensive, (3) easily available, (4) too complicated, (5) too hard to learn, (6) takes too much time to learn, (7) if they are opposed to learning new technologies, and (8) whether it is difficult to keep up with changes in technology.

\section{Urban-rural residence}

The residency was categorized as urban, suburban, and rural using the 2013 Beale Rural-Urban 
Table 1. Sample characteristics by rural-urban residence $(N=1,566)$

\begin{tabular}{|c|c|c|c|c|c|c|}
\hline \multirow{2}{*}{ Variables } & \multicolumn{2}{|c|}{ Urban $(n=850)$} & \multicolumn{2}{|c|}{ Sub-urban $(n=338)$} & \multicolumn{2}{|c|}{ Rural $(n=378)$} \\
\hline & Mean (S.E.) & $\%$ & Mean (S.E.) & $\%$ & Mean (S.E.) & $\%$ \\
\hline Residence & & 51.9 & & 22.6 & & 25.5 \\
\hline Age in years (range: $50-98$ ) & $64.9(0.39)$ & & $65.78(0.63)$ & & $65.92(0.57)$ & \\
\hline \multicolumn{7}{|l|}{ Gender } \\
\hline Female & & 50.6 & & 53.2 & & 56.5 \\
\hline \multicolumn{7}{|l|}{ Race/ethnicity } \\
\hline Racial/ethnic minority & & 18.3 & & 15.9 & & $11.7^{* *}$ \\
\hline \multicolumn{7}{|l|}{ Marital status } \\
\hline Married/partnered & & 65.3 & & 61.7 & & 65.0 \\
\hline Education in years (range: $0-17$ ) & $13.6(0.13)$ & & $13.0(0.25) *$ & & $12.87(0.16)^{* * *}$ & \\
\hline Annual household income (thousands) & $87.2(5.50)$ & & $91.3(13.1)$ & & $62.2(4.81)^{* * *}$ & \\
\hline Chronic diseases (range: $0-8$ ) & $1.84(0.06)$ & & $2.07(0.09) *$ & & $2.24(0.09) * * *$ & \\
\hline \multicolumn{7}{|l|}{ Functional limitation } \\
\hline Yes ( $\geq 1$ in activities of daily living) & & 11.0 & & 14.0 & & $16.2 *$ \\
\hline Self-rated health (range: $1-5$ ) & $3.36(0.05)$ & & $3.30(0.07)$ & & $3.14(0.07) * *$ & \\
\hline Depressive symptoms (range: $0-8$ ) & $1.29(0.09)$ & & $1.37(0.14)$ & & $1.44(0.12)$ & \\
\hline
\end{tabular}

Continuum (RUC) codes. Developed by the S.U.S. Department of Agriculture's Economic Research Service, the RUC codes represent the degree of urbanization by population size and adjacency to metropolitan areas. Urban refers to metropolitan counties with a population size of 1 million or more (RUC code 1). Suburban indicates metropolitan counties of 250,000 to 1 million population (RUC code 2). Finally, rural areas include counties with fewer than 250,000 population, both adjacent or not adjacent to a metropolitan area (RUC code 3-9).

\section{Covariates}

Age (in years), gender $(0=$ male; $1=$ female), race/ ethnicity $(0=$ non-Hispanic White; $1=$ racial $/$ ethnic minority [non-Hispanic black, Hispanic, American Indian, Alaskan Native, Asian, or Pacific Islander]), and marital status ( $0=$ separated, divorced, widowed, or never married; $1=$ married or partnered) were included as demographic variables. Educational attainment (in years) and annual household income served as indicators of socioeconomic status. Education was assessed by the number of years of formal schooling completed (range: 0-17), and annual household income included income from all sources such as earnings, pensions, and social security. Because the distribution of annual household income was highly skewed, log-transformed values were used for multivariate analyses. As for indicators of health conditions, chronic diseases, functional limitations, self-rated health, and depressive symptoms were considered. Participants were asked to report whether or not they had any of the following chronic diseases diagnosed by a physician: high blood pressure, diabetes, cancer, lung disease, coronary heart disease, psychiatric problems, arthritis or rheumatism, and stroke. The number of chronic diseases was calculated by summing up all specific diseases (range 0-8). Functional limitation was assessed by asking participants' difficulties in performing activities of daily living (ADLs) such as bathing, dressing, walking across a room, and getting in and out of bed. The composite scores were dichotomized into $0=$ no functional limitation and $1=$ one or more functional limitations. Self-rated health status was measured with a single item, "Would you say your health is excellent, very good, good, fair, or poor?" Responses were coded as $1=$ poor and $5=$ excellent so that higher scores indicated better subjective health status. Depressive symptoms were measured with the 8 -item version of the Center for Epidemiological Studies Depression (CES-D) scale (Andresen et al., 1994; Radloff, 1977). Participants were asked to report whether they have experienced eight depressive symptoms (e.g., lonely, feeling depressed, and sad) in the past week. Response options were $0=$ no or $1=$ yes. After reversing two positive mood items, total scores were computed by adding responses for each item. The CES-D scale's internal consistency was high in our sample, with the KuderRichardson 20 (KR-20) coefficient of .82.

\section{Analytical strategy}

Descriptive statistics were conducted to review the sample's demographic, socioeconomic, and health characteristics by urban-rural residence. Comparisons were made using adjusted Wald or chi-square statistics. Next, group differences in internet access and usage were compared across urban, suburban, and rural residents through chi-square tests. Separate multivariate logistic regression analyses were performed for each technology used to examine their association with rural-urban residence $(N=1,566)$. Similarly, we used multivariate logistic regression models to investigate the association between rural-urban residence and attitudes toward technology among non-users $(N=633)$. For the analysis of non-users' attitudes toward technology, the pairwise deletion was applied to make optimal utilization of available data ( $\mathrm{Ns}=556-629)$. We used sample weights to adjust for differential 
Table 2. Internet access and usage by rural-urban residence $(N=1,566)$

\begin{tabular}{|c|c|c|c|}
\hline Variables & $\begin{array}{l}\% \text { Urban } \\
(n=850)\end{array}$ & $\begin{array}{c}\% \text { Sub-urban } \\
(n=338)\end{array}$ & $\begin{array}{c}\% \text { Rural } \\
(n=378)\end{array}$ \\
\hline Internet access & 66.0 & 61.0 & $53.6^{* * *}$ \\
\hline Communication technology (yes, any) & 70.5 & 66.4 & $59.8 * *$ \\
\hline E-mail & 68.6 & 63.1 & $55.1 * * *$ \\
\hline Social network sites & 32.0 & 31.3 & 29.0 \\
\hline Online calls & 24.8 & 20.7 & 19.2 \\
\hline Online chatting & 23.0 & 16.8 & $16.6^{*}$ \\
\hline Smartphone & 32.4 & $23.8 *$ & $16.1 * * *$ \\
\hline Financial technology (yes, any) & 51.8 & $43.0 *$ & $38.2 * * *$ \\
\hline Online bill payment & 44.1 & $34.4 *$ & $31.7 * *$ \\
\hline Online banking & 47.1 & 39.3 & $34.5 * *$ \\
\hline Health technology (yes, any) & 68.1 & $57.5 * *$ & 61.7 \\
\hline Online wellness program & 9.6 & 9.0 & 5.7 \\
\hline Online health information seeking & 57.0 & $43.1 * * *$ & $44.0 * * *$ \\
\hline Device use for health monitoring & 30.6 & 27.1 & 27.0 \\
\hline Wii fit use & 9.0 & 6.0 & 8.2 \\
\hline Media technology (yes, any) & 52.5 & 45.4 & $37.2 * * *$ \\
\hline E-readers or tablets & 26.2 & 22.9 & $17.3 * *$ \\
\hline MP3 players & 25.7 & $16.3 * *$ & $11.1 * * *$ \\
\hline Live-streaming radio, $\mathrm{TV}$, or movies & 33.9 & $23.2 * *$ & $20.0 * * *$ \\
\hline Video games & 10.7 & 6.0 & $6.3 *$ \\
\hline
\end{tabular}

in rural and $43 \%$ in suburban vs. $52 \%$ in urban). About a third of suburban and rural residents used online bill payment, while more than $40 \%$ of urban residents did so. Rates of online banking users were also significantly lower among the rural group than their urban counterparts. Similarly, there were fewer individuals from the suburban group who used at least one health technology than the urban group. More urban residents sought online health information than the other sampling probabilities and survey non-response. All analyses were performed using Stata version 14.2. (StataCorp. College Station, TX).

\section{Results}

\section{Sample characteristics}

Table 1 summarizes the sample characteristics by rural-urban residence. The sample was comprised of $52 \%$ urban, $23 \%$ sub-urban, and $25 \%$ rural residents. Compared to urban residents, the rural group included a lower proportion of racial/ethnic minorities and those with functional limitations. In addition, rural residents had lower annual household income levels and poorer selfrated health than their urban counterparts. Both suburban and rural residents had fewer years of education and reported more chronic diseases compared to the urban group. No significant group differences were found for age, gender, marital status, and depressive symptoms.

\section{Urban-rural group differences in internet ac- cess and technology usage}

Table 2 presents a cross-tabulation of internet access and different types of technology usage by urban-rural residents. About $66 \%$ and $61 \%$ of urban and suburban residents were regular internet users, whereas only $54 \%$ of rural residents regularly used the internet. In terms of communication technology use, significantly fewer individuals in the rural group $(60 \%)$ reported use of at least one communication technology than their urban counterparts (71\%). For specific technology, significance was found in email use $(55 \%$ in rural vs. $69 \%$ in urban), online chatting $(17 \%$ in rural vs. $23 \%$ in urban), and smartphone use (16\% in rural and $24 \%$ in sur-urban vs. $32 \%$ in urban). Compared to urban residents, suburban and rural residents had fewer individuals who used one or more financial technologies $38 \%$ two groups $(57 \%$ in urban vs. $43 \%$ in sub-urban and $44 \%$ in rural). Finally, the rural group had significantly fewer media technology users (37\%) compared to the urban group (53\%). Specifically, significant differences between urban and rural residents were found in all sub-categories, whereas the differences between urban and suburban were only found in the use of MP3 players and live-streaming radio, T.V., or movies.

\section{Logistic regression models of technology usage}

We further examined the observed group differences in technology usage with multivariate logistic regression analyses. Table 3 shows the association between rural-urban residence and four different technology use types after controlling for demographic, socioeconomic, and health covariates. Compared to urban residents, rural residents had lower odds of using all technology types except health technology. On the other hand, the suburban group showed decreased odds of using health technologies than the urban group. No significant associations were found in the use of communication, financial, and media technologies.

\section{Logistic regression models of non-users' attitudes} toward technology

Table 4 presents the models predicting attitudes toward technology among non-users of communication technology. We found that three particular attitudes toward technology were significantly associated with the rural-urban residency. Compared to urban residents, rural residents were less likely to report that technology is easily available and more likely to think that technology is too complicated and too hard to learn. It was noteworthy that no significant differences were found between suburban and urban residents in their attitudes. The associations of the ruralurban residence with other five types of attitudes 
Table 3. Logistic regression models of technology usage $(\mathrm{N}=1,566)$

\begin{tabular}{|c|c|c|c|c|}
\hline \multirow[b]{2}{*}{ Variables } & \multicolumn{4}{|c|}{ Odds ratio (95\% Confidence interval) } \\
\hline & $\begin{array}{c}\text { Communication } \\
\text { technology }\end{array}$ & $\begin{array}{c}\text { Financial } \\
\text { technology }\end{array}$ & $\begin{array}{c}\text { Health } \\
\text { technology }\end{array}$ & $\begin{array}{c}\text { Media } \\
\text { technology }\end{array}$ \\
\hline \multicolumn{5}{|l|}{ Rural-urban residence (Ref: urban) } \\
\hline Sub-urban & $1.07(0.71-1.63)$ & $0.77(0.53-1.12)$ & $0.65(0.45-0.95) *$ & $0.83(0.57-1.21)$ \\
\hline Rural & $0.69(0.47-0.99) *$ & $0.64(0.45-0.9)^{*}$ & $0.76(0.55-1.05)$ & $0.57(0.40-0.80) * *$ \\
\hline \multicolumn{5}{|l|}{ Demographic characteristics } \\
\hline Age (in years) & $0.91(0.90-0.93)^{* * *}$ & $0.92(0.91-0.94) * * *$ & $0.94(0.93-0.96)^{* * *}$ & $0.92(0.91-0.94) * * *$ \\
\hline Female & $1.89(1.36-2.63) * * *$ & $1.30(0.96-1.75)$ & $1.54(1.15-2.06) * *$ & $1.13(0.84-1.51)$ \\
\hline Racial/ethnic minority & $0.42(0.28-0.62)^{* * *}$ & $0.54(0.38-0.78) * *$ & $0.68(0.48-0.96) *$ & $0.62(0.43-0.9)^{*}$ \\
\hline Married/partnered & $1.43(1.00-2.06)$ & $1.19(0.84-1.69)$ & $1.38(1-1.89) *$ & $1.46(1.04-2.04) *$ \\
\hline \multicolumn{5}{|l|}{ Socio-economic status } \\
\hline Educational attainment (in years) & $1.47(1.36-1.60)^{* * *}$ & $1.22(1.14-1.31) * * *$ & $1.15(1.09-1.21)^{* * *}$ & $1.15(1.08-1.23) * * *$ \\
\hline Annual household income & $1.17(1.01-1.35) *$ & $1.12(0.97-1.29)$ & $1.01(0.91-1.12)$ & $1.09(0.95-1.24)$ \\
\hline \multicolumn{5}{|l|}{ Health conditions } \\
\hline Chronic diseases (numbers) & $0.99(0.87-1.12)$ & $1.04(0.92-1.18)$ & $1.31(1.17-1.47)^{* * *}$ & $1.09(0.97-1.22)$ \\
\hline Functional limitation & $0.61(0.37-0.98)^{*}$ & $0.79(0.49-1.26)$ & $0.93(0.6-1.43)$ & $0.89(0.56-1.41)$ \\
\hline Self-rated health & $1.28(1.05-1.55) *$ & $1.19(1.00-1.42)$ & $1.14(0.95-1.36)$ & $1.28(1.07-1.51)^{* *}$ \\
\hline Depressive symptoms & $0.95(0.86-1.04)$ & $0.95(0.86-1.03)$ & $0.94(0.87-1.02)$ & $1.00(0.91-1.09)$ \\
\hline
\end{tabular}

${ }^{*} p<.05 ;{ }^{* *} p<.01 ;{ }^{* * *} p<.001$.
Note. Estiamtes were weighted. Racial//ethnic minority = non-Hispanic black, Hispanic, American Indian, Alaskan Native, Asian, and Pacific Islander.

toward technology (i.g., have interest in trying technology, technology is too expensive, takes too much time to learn, too difficult to keep up with changes, and if they are opposed to learning new technologies) were not significant and thus not shown in the table for simplicity.

\section{Discussion}

Informed by the social determinants of health framework, we analyzed the HRS data to explore whether one's residence (urban, suburban, or rural) is associated with less use of the internet, limited usage patterns of different technologies, and more negative attitudes toward technology in later life. Our bivariate results indicate that individuals in rural communities use the internet at a lower rate $(54 \%)$ as compared to urban populations $(66 \%)$. Furthermore, rural living older adults used technology at lower rates for different technology usage sub-types, including communication, financial, and media technologies. Compared to urban residents, older adults living in suburban areas also reported lower usage rates of certain types of technology use, such as smartphones, online bill payments, and online health information seeking.

Our multivariate models of technology usage further showed that rural residency (vs. urban) was significantly associated with decreased odds of using communication, financial, and media technology, while suburban residency (vs. urban) was related to lower odds of health technology use. Overall, these findings add to the body of past research, pointing out a digital exclusion of rural populations in general (Greenberg et al., 2018; Perrin \& Duggan, 2015) and in the older populations (Berner et al., 2015; Calvert et al., 2009). Importantly, our analyses on various usage patterns of ICTs extend the scope of the existing literature where a single aspect of technology use (i.e., internet use) was often focused.

Our findings documented that older rural residents particularly do not engage in online com- munication and media. Such exclusion could lead to many disadvantages, including connection with loved ones and personal mattering. This mattering and connectedness often occur through the usage of ICTs, which allow for the maintenance of social connectedness and receiving social support from their networks (Francis et al., 2019). Mattering has been explained as occurring due to social interactions among people, which helps reinforce their value to others (Fazio, 2009), but in situations where in-person interactions may not be possible, especially social interactions that reinforce ones' value to others (Fazio, 2009). Therefore, in lieu of and in addition to face-to-face interactions, using ICTs may be one way to enhance a sense of mattering among older adults and potentially improve their general well-being. This is even more relevant in times like the current COVID-19 pandemic, where people are required to socially distance and avoid social interaction, especially for older adults who are more susceptible to the illness. We also found lower usage of technology for financial reasons among rural residents. Today, most financial institutions allow consumers to perform tasks such as banking and bill payments online, making transactions easier, quicker, and even safer. Therefore, those residing in rural areas are more likely to lose all these advantages of being digitally connected.

Additionally, technology is being used in the health sector in every way today. Following our findings, older adults in both suburban and rural areas use ICTs at a lower level for health purposes (e.g., online health information seeking) than their urban counterparts. This is unfortunate, considering that the benefits of health technologies may be particularly pronounced for non-urban communities. For example, telehealth can provide healthcare services with no traveling and maximizing efficiency (Heinz et al., 2013). Furthermore, Ramsetty and Adams (2020) describe how social determinants of health play a role in the development of the digital divide 
Table 4. Logistic regression models of attitudes toward technology among non-users ( $N=633)$

\begin{tabular}{|c|c|c|c|}
\hline \multirow[b]{2}{*}{ Variables } & \multicolumn{3}{|c|}{ Odds ratio $(95 \%$ Confidence interval) } \\
\hline & $\begin{array}{l}\text { Easily available } \\
\quad(n=599)\end{array}$ & $\begin{array}{c}\text { Too complicated } \\
(n=611) \\
\end{array}$ & $\begin{array}{c}\text { Too hard to learn } \\
(n=599)\end{array}$ \\
\hline \multicolumn{4}{|l|}{ Rural-urban residence (Ref: urban) } \\
\hline Sub-urban & $0.91(0.46-1.80)$ & $1.07(0.62-1.86)$ & $1.34(0.77-2.35)$ \\
\hline Rural & $0.47(0.26-0.85) *$ & $1.81(1.02-3.21) *$ & $1.93(1.13-3.30) *$ \\
\hline \multicolumn{4}{|l|}{ Demographic characteristics } \\
\hline Age (in years) & $0.99(0.97-1.01)$ & $1.03(1.01-1.06) * *$ & $1.05(1.02-1.07)^{* * *}$ \\
\hline Female & $0.64(0.37-1.11)$ & $1.23(0.77-1.97)$ & $0.89(0.56-1.41)$ \\
\hline Racial/ethnic minority & $0.48(0.28-0.84) * *$ & $1.10(0.62-1.96)$ & $0.77(0.45-1.33)$ \\
\hline Married/partnered & $1.83(1.10-3.07) *$ & $1.13(0.66-1.93)$ & $1.09(0.67-1.78)$ \\
\hline \multicolumn{4}{|l|}{ Socio-economic status } \\
\hline Educational attainment (in years) & $1.09(1.01-1.17) *$ & $0.83(0.75-0.93) * * *$ & $0.83(0.76-0.91) * * *$ \\
\hline Annual household income & $1.06(0.91-1.24)$ & $0.81(0.58-1.14)$ & $0.88(0.70-1.11)$ \\
\hline \multicolumn{4}{|l|}{ Health conditions } \\
\hline Chronic diseases (numbers) & $0.95(0.78-1.15)$ & $1.13(0.94-1.35)$ & $1.05(0.88-1.15)$ \\
\hline Functional limitation & $0.75(0.39-1.45)$ & $2.00(1.00-4.01)$ & $1.83(0.95-3.52)$ \\
\hline Self-rated health & $1.07(0.79-1.44)$ & $1.02(0.77-1.34)$ & $0.96(0.73-1.24)$ \\
\hline Depressive symptoms & $1.07(0.94-1.21)$ & $1.06(0.92-1.23)$ & $1.22(1.07-1.39) * *$ \\
\hline
\end{tabular}

${ }^{*} p<.05 ;{ }^{* *} p<.01 ;{ }^{* * *} p<.001$.

Note. Estimates were weighted. Racial/ethnic minority = non-Hispanic black, Hispanic, American Indian, Alaskan Native, Asian, and Pacific Islander.

(especially in the context of COVID-19) and can reinforce inequity based on social factors, including health and healthcare access (along with education and economic stability). The pandemic has further increased how technology is being used for healthcare, and older adults can now get some of the care they need inside their homes - exclusion through the digital divide is likely to increase adverse health outcomes.

Our analyses of non-users' attitudes toward technology deserve particular attention. We showed that older adults in rural areas were more likely to perceive that technology is less easily available, too complicated, and too hard to learn as compared to the urban group. These findings are in line with previous qualitative work where older suburban or rural residents reported that their use of technologies was limited due to lack of knowledge about technologies or difficulties in learning (Marston et al., 2019; O'Brien et al., 2014). However, there has been a dearth of quantitative studies, particularly with a nationally representative sample, that examined perceptions or attitudes toward technology use among older adults living in non-urban communities.

Overall, the present study findings support that older adults living in suburban and rural areas not only have lower access to the Internet (Hypothesis 1), but they also use fewer Internetbased technologies (Hypothesis 2) compared to those from the urban. Thus, our work demonstrates the presence of the digital divide's first level (inequal access to the Internet) and second level (different technology skills and usage) in the context of geographic location. Furthermore, we showed that non-users of communication technologies from suburban and rural areas have more unfavorable attitudes toward technologies than those in urban communities, supporting Hypothesis 3. Importantly, our results pertain to the conceptual discussion on the digital divide (Gonzales, 2016; van Dijk, 2005, 2020). According to van Dijk and Hacker (2003), the digital divide is not only related to the simple lack of access but also understood as usage patterns or psychological gaps, as shown in our study. In particular, rural non-users' more negative attitudes towards technology may serve as critical determinants of their voluntary decision not to use technology. Therefore, more research efforts should be paid to explore multiple aspects of the urban-rural digital divide.

\section{Limitations}

Despite our best efforts, we acknowledge certain limitations of our research. First, the HRS dataset is from 2012, so it is possible that this information could be a little outdated as compared to current technology usage patterns for older adults. For similar reasons, the dataset does not include more latest technologies such as wearable trackers, for instance. Critically, our study utilized crosssectional data, which does not allow for making causal inferences. Future studies should use a longitudinal research design to provide a complete understanding of the relationship between one's residence and technology use in later life. In addition, although we included a wide range of information on specific types of technology use, data on frequency or duration of use was not obtained. Based on our findings, a next step forward may include those variables to examine whether the urban-rural residence relates to how long or frequently one uses digital technologies.

\section{Conclusions}

Despite these limitations, however, we believe that the results of our study provide valuable in- 


\section{Urban/rural digital divide among older adults}

sights into the existing digital divide that excludes older adults, often based on their geographic location. Our results identify an urgent need for interventions to introduce digital technologies to older adults in rural areas. This is especially imperative in unprecedented isolating times, such as those created by the COVID-19 global pandemic. Digital technologies have helped people stay in touch with their loved ones and provide medical assistance. Such technologies in this situation are more important for older adults, who are more susceptible to the novel coronavirus and would benefit from integrating digitization

\section{Conflict of interest}

The authors declare that there is no conflict of interest.

\section{Author statement}

Hee Yun Lee: Funding acquisition, Conceptualization, investigation, methodology, writing - review \& editing. Shaheen Kanthawala: Conceptualization, investigation, writing - original draft. Eun Young Choi: Data curation, formal analysis, methodology, writing - original draft. Young Sun Kim: Supervision, Funding acquisition, resources, writing - review \& editing.

\section{Acknowledgements}

Data was from the Health and Retirement Study, which was funded by the National Institute on Aging (NIA U01AG009740) and the Social Security Administration. The current study was not preregistered. Data, analytic methods, and study materials will be made available upon request through the corresponding author.

\section{Funding}

This work was supported by the Ministry of Education of the Republic of Korea and the National Research Foundation of Korea (NRF-2018S1A3A2075402).

\section{References}

Anderson, M. (2018, September 10). About a quarter of rural Americans say access to high-speed internet is a major problem. Pew Research Center. https:// www.pewresearch.org/fact-tank/2018/09/10/ about-a-quarter-of-rural-americans-say-access-tohigh-speed-internet-is-a-major-problem/

Andresen, E. M., Malmgren, J., Carter, W. B., \& Patrick, D. L. (1994). Screening for depression in well older adults: Evaluation of a short form of the CES-D (Center for Epidemiologic Studies Depression Scale. American Journal of Preventive Medicine, 10, 77-84.

Ball, C., Francis, J., Huang, K.-T., Kadylak, T., Cotten, S. R., \& Rikard, R. V. (2019). The Physical-Digital Divide: Exploring the Social Gap Between Digital Natives and Physical Natives. Journal of Applied Gerontology, 38(8), 1167-1184. https://doi. org/10.1177/0733464817732518

Barrantes, R., \& Vargas, E. (2017). Inequalities in the Appropriation of Digital Spaces in Metropolitan Areas of Latin America. In H. Kaur, E. Lechman, \& A. Marszk (Eds.), Catalyzing Development through ICT Adoption (pp. 207-226). Springer International Publishing. https://doi.org/10.1007/978-3-319-56523-1_11 into their daily lives. Future work could include interventions into marginalized communities to better understand the causes of this divide in greater detail, the community's needs, and what can be provided to them to prevent further exclusion. In addition, our work calls for further research attention to the role of geographic location. Although we focused on three categories from the Beale Rural-Urban continuum for this study, future work can examine different typologies of spatial locations (e.g., urban networks) and their implications on the digital divide.

Berner, J., Rennemark, M., Jogréus, C., Anderberg, P., Sköldunger, A., Wahlberg, M., Elmståhl, S., \& Berglund, J. (2015). Factors influencing Internet usage in older adults (65 years and above) living in rural and urban Sweden. Health Informatics Journal, 21(3), 237-249. https://doi. org/10.1177/1460458214521226

Calvert, J. F., Kaye, J., Leahy, M., Hexem, K., \& Carlson, N. (2009). Technology use by rural and urban oldest old. Technology and Health Care: Official Journal of the European Society for Engineering and Medicine, 17(1), 1-11. https://doi.org/10.3233/ THC-2009-0527

Centers for Disease Control and Prevention. (2013). The State of Aging and Health in America 2013. Centers for Disease Control and Prevention, US Dept of Health and Human Services. https://www.cdc.gov/ aging/pdf/state-aging-health-in-america-2013.pdf

Eynon, R., \& Helsper, E. (2011). Adults learning online: Digital choice and/or digital exclusion? New Media \& Society, 13(4), 534-551. https://doi. org/10.1177/1461444810374789

Francis, J., Rikard, R. V., Cotten, S. R., \& Kadylak, T. (2019). Does ICT Use matter? How information and communication technology use affects perceived mattering among a predominantly female sample of older adults residing in retirement communities. Information Communication and Society, 22(9), 1281-1294. https://doi.org/10.1080/136911 8X.2017.1417459

Gell, N. M., Rosenberg, D. E., Demiris, G., LaCroix, A. Z., \& Patel, K. V. (2015). Patterns of Technology Use Among Older Adults With and Without Disabilities. The Gerontologist, 55(3), 412-421. https:// doi.org/10.1093/geront/gnt166

Gonzales, A. (2016). The contemporary US digital divide: From initial access to technology maintenance. Information, Communication \& Society, 19(2), 234-248. https://doi.org/10.1080/13691 18X.2015.1050438

Greenberg, A. J., Haney, D., Blake, K. D., Moser, R. P., \& Hesse, B. W. (2018). Differences in Access to and Use of Electronic Personal Health Information Between Rural and Urban Residents in the United States: EPHI Use in Rural and Urban Patients. The Journal of Rural Health, 34, s30-s38. https://doi. org/10.1111/jrh.12228

Hale, T. M., Cotten, S. R., Drentea, P., \& Goldner, 


\section{Urban/rural digital divide among older adults}

M. (2010). Rural-Urban Differences in General and Health-Related Internet Use. American Behavioral Scientist, 53(9), 1304-1325. https://doi. org/10.1177/0002764210361685

Hanson, V. L. (2010). Influencing technology adoption by older adults. Interacting with Computers, 22(6), 502-509. https://doi.org/10.1016/j. intcom.2010.09.001

Heinz, M., Martin, P., Margrett, J. A., Yearns, M., \& Franke, W. (2013). Perceptions of technology among older adults. Journal of Gerontological Nursing, 39(1), 42-51. https://doi.org/10.3928/0098913420121204-04

Heo, J., Chun, S., Lee, S., Lee, K. H., \& Kim, J. (2015). Internet Use and Well-Being in Older Adults. Cyberpsychology, Behavior, and Social Networking, 18(5), 268-272. https://doi.org/10.1089/cyber.2014.0549

Korupp, S. E. (2005). Causes and Trends of the Digital Divide. European Sociological Review, 21(4), 409_ 422. https://doi.org/10.1093/esr/jci030

Levine, D. M., Lipsitz, S. R., \& Linder, J. A. (2016). Trends in Seniors' Use of Digital Health Technology in the United States, 2011-2014. JAMA, 316(5), 538. https://doi.org/10.1001/jama.2016.9124

Livingstone, S., \& Helsper, E. (2007). Gradations in digital inclusion: Children, young people and the digital divide. New Media \& Society, 9(4), 671-696. https://doi.org/10.1177/1461444807080335

Marston, H. R., Genoe, R., Freeman, S., Kulczycki, C., \& Musselwhite, C. (2019). Older Adults' Perceptions of ICT: Main Findings from the Technology In Later Life (TILL) Study. 27.

O'Brien, T. R., Treiber, F., Jenkins, C., \& Mercier, A. (2014). Use of Computer and Cellular Phone Technology by Older Rural Adults: CIN: Computers, Informatics, Nursing, 32(8), 390-396. https://doi. org/10.1097/CIN.0000000000000080

Ong, P. M. (2020). COVID-19 and the Digital Divide in Virtual Learning, Fall 2020. UCLA Center for Neighborhood Knowledge. https://knowledge.luskin.ucla.edu/wp-content/uploads/2020/12/DigitalDivide-Phase2_brief_release_v01.pdf

Perrin, A., \& Atske, S. (2021). 7\% of Americans don't use the internet. Who are they? Pew Research Center. https://www.pewresearch.org/fact-tank/2021/04/02/7of-americans-dont-use-the-internet-who-are-they/

Perrin, A., \& Duggan, M. (2015, June 26). Americans Internet Access: Percent of Adults 2000-2015. Pew Research Center. https://www.pewresearch. org/internet/2015/06/26/americans-internet-access-2000-2015/

Pew Research Center. (2019). Internet/Broadband Fact Sheet. https://www.pewresearch.org/internet/factsheet/internet-broadband/

Quan-Haase, A., Mo, G. Y., \& Wellman, B. (2017). Connected seniors: How older adults in East York exchange social support online and offline. Information, Communication \& Society, 20(7), 967-983. https://doi.org/10.1080/1369118X.2017.1305428

Radloff, L. S. (1977). The CES-D Scale: A SelfReport Depression Scale for Research in the
General Population. Applied Psychological Measurement, 1(3), 385-401. https://doi. org/10.1177/014662167700100306

Ramsetty, A., \& Adams, C. (2020). Impact of the digital divide in the age of COVID-19. Journal of the American Medical Informatics Association, 27(7), 1147-1148. https://doi.org/10.1093/jamia/ocaa078

Silver, M. P. (2014). Socio-economic status over the lifecourse and internet use in older adulthood. Ageing and Society, 34(6), 1019-1034. https://doi. org/10.1017/S0144686X12001420

Sum, S., Mathews, R. M., Hughes, I., \& Campbell, A. (2008). Internet Use and Loneliness in Older Adults. CyberPsychology \& Behavior, 11(2), 208-211. https://doi.org/10.1089/cpb.2007.0010

Tsai, H. S., Shillair, R., Cotten, S. R., Winstead, V., \& Yost, E. (2015). Getting Grandma Online: Are Tablets the Answer for Increasing Digital Inclusion for Older Adults in the U.S.? Educational Gerontology, 41(10), 695-709. https://doi.org/10.1080/03601277 2015.1048165

van Deursen, A. J. (2020). Digital Inequality During a Pandemic: Quantitative Study of Differences in COVID-19-Related Internet Uses and Outcomes Among the General Population. Journal of Medical Internet Research, 22(8), e20073. https://doi. org/10.2196/20073

van Dijk, J. (2005). The deepening divide: Inequality in the information society. Sage.

van Dijk, J. (2006). Digital divide research, achievements and shortcomings. Poetics, 34(4-5), 221-235. https://doi.org/10.1016/j.poetic.2006.05.004

van Dijk, J. (2020). The digital divide. Polity Press.

van Dijk, J., \& Hacker, K. (2003). The Digital Divide as a Complex and Dynamic Phenomenon. The Information Society, 19(4), 315-326. https://doi. org/10.1080/01972240309487

Vogels, E. A. (2021a). Digital divide persists even as Americans with lower incomes make gains in tech adoption. Pew Research Center. https://www.pewresearch.org/fact-tank/2021/06/22/digital-dividepersists-even-as-americans-with-lower-incomesmake-gains-in-tech-adoption/

Vogels, E. A. (2021b). Some digital divides persist between rural, urban and suburban America. Pew Research Center. https://www.pewresearch.org/ fact-tank/2021/08/19/some-digital-divides-persistbetween-rural-urban-and-suburban-america/

World Health Organization. (2010). A conceptual framework for action on the social determinants of health: Debates, policy \& practice, case studies. http://apps.who.int/iris/bitstre am/10665/44489/1/9789241500852_eng.pdf

World Health Organization. (2020). Social determinants of health. http://www.who.int/social_determinants/en/

Yu, R. P., Ellison, N. B., McCammon, R. J., \& Langa, K. M. (2016). Mapping the two levels of digital divide: Internet access and social network site adoption among older adults in the USA. Information, Communication \& Society, 19(10), 1445-1464. https:// doi.org/10.1080/1369118X.2015.1109695 